\title{
Enantioselective Hydrogenation of Imines Using Cooperative Catalysis
}

Using Cooperative Catalysis

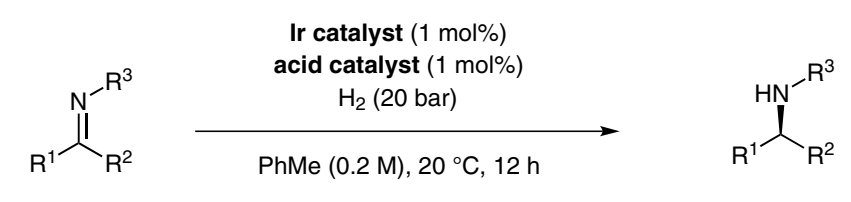

up to $97 \%$ yield

up to $98 \%$ ee

33 examples
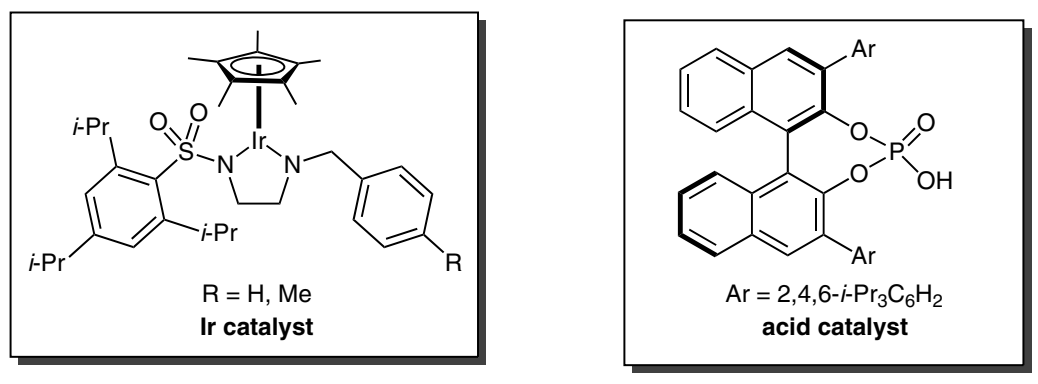

Selected examples:
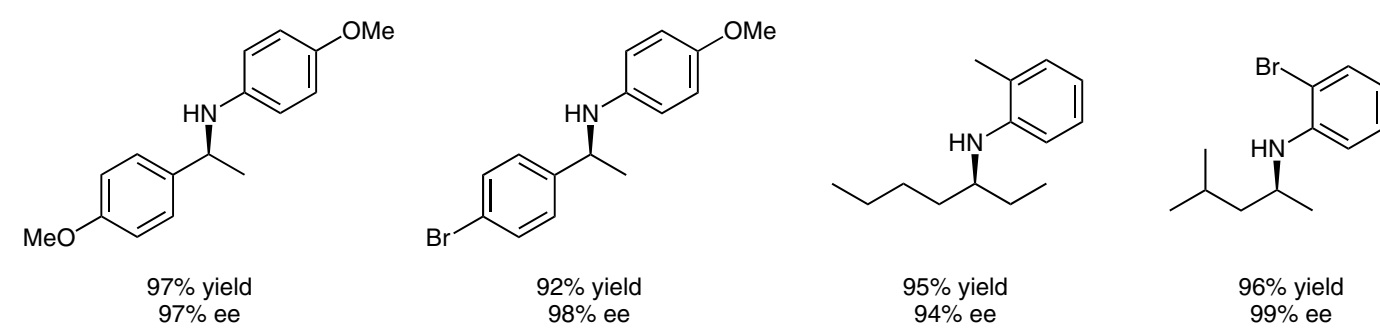

Significance: Optically active amines are common in many fine chemicals, agrochemicals, and pharmaceuticals. The authors report a cooperative metal-organo catalytic system utilizing a chiral Brønsted acid and an achiral iridium catalyst (see below for a Review on transfer hydrogenation).

Review: C. Zheng, S.-L. You Chem. Soc. Rev. 2012, 41, 2498-2518.
Comment: The authors have reported the cooperative use of a chiral iridium catalyst with a chiral phosphoric acid in the asymmetric hydrogenation of acyclic imines with $\mathrm{H}_{2}$ (J. Am. Chem. Soc. 2008, 130, 14450). Here, they report an achiral iridium catalyst with a chiral phosphoric acid in a similar reaction. Alkyl imines, which are known to be difficult substrates for asymmetric hydrogenation, were shown to be excellent substrates in this system, giving enantioselectivities up to $97 \%$.

\section{Key words}

\section{iridium}

Brønsted acid

cooperative catalysis 